\title{
Alternativo
}

\section{LIBERDADE RELIGIOSA: UMA ABORDAGEM INTERDISCIPLINAR}

\author{
Athena de Albuquerque Farias (1) \\ João Matias de Oliveira Neto (2) \\ Helayne Candido Pereira (3)
}

\begin{abstract}
Resumo
A partir do século XVI, com a Reforma Protestante e os seguintes desdobramentos históricos em prol da liberdade de consciência individual como sendo norteadora das ações humanas, há o rompimento de frente com a tradição e a autoridade suprema do clero e da nobreza predominantes à época, surgindo nesse contexto uma nova realidade: o direito à liberdade religiosa. Com base neste novo fato, o presente artigo tem como objetivo elaborar uma discussão acerca da questão da liberdade religiosa no âmbito do Direito e das Ciências Sociais. Trata-se de uma avaliação interdisciplinar tendo em vista a complexidade do tema em questão, envolvendo conceitos clássicos da área jurídica e da sociologia. Para tanto, o estudo está baseado em uma pesquisa bibliográfica empregando materiais como livros e periódicos. Busca-se, ainda, com o intuito de maior compreensão acerca do tema abordado, destacar pontos como a tolerância religiosa como conduta auxiliadora ao direito de liberdade religiosa, a modernidade das instituições religiosas e o conceito de unidade social estruturado por elas, além de tentar promover um diálogo através deste estudo entre as duas ciências colocadas como alicerces do trabalho no qual se observa a dimensão de sua complementaridade.
\end{abstract}

Palavras-chaves: Liberdade; Religião; Secularização 


\section{Introdução}

Historicamente, no mundo ocidental, o direito à liberdade religiosa tomou grande importância a partir da problemática surgida para a Igreja Católica com a ruptura do universo religioso cristão através da Reforma Protestante e com os movimentos encabeçados por filósofos como Locke e Voltaire. Foi retomada a consciência individual como norteadora das ações humanas, substituindo a tradição e a autoridade suprema do clero e da nobreza predominantes à época.

A partir desse momento, surgem documentos legais com a finalidade de reconhecimento desta liberdade de consciência como a Declaração dos Direitos Humanos em sua primeira geração, a Declaração de Independência dos Estados Unidos e no Bill of Rights do Estado da Virgínia, em 1776. E em 1789, a Declaração dos Direitos do Homem e do Cidadão. Ainda em 1791, com a Constituição francesa. Trazendo a noção de Fraternidade ou Solidariedade que, juntamente com o Princípio da Liberdade e Igualdade, chegaram aos dias de hoje, transformando-se em valores soberanos que regem a Declaração Universal dos Direitos Humanos de 1948.

É nesse contexto de origem do direito à liberdade de religião, reivindicada dentro da reafirmação dos direitos de liberdade do homem, agindo de acordo com sua consciência, que este estudo se centra. Para tanto, será utilizada uma abordagem interdisciplinar, por se tratar de tema complexo e delicado, que necessita de incursões em vários campos do saber para se chegar a uma melhor abordagem, no qual foi escolhido dar ênfase ao Direito e às Ciências Sociais, apresentando fundamentos teóricos nos quais o tema se insere por meio de conceitoschaves. Objetiva-se apresentar a importância da liberdade religiosa e de sua permanência na lógica associada ao princípio constitucional que o rege, bem como no caráter mutável das instituições e das formas sociais presentes no seio da sociedade ocidental.

O estudo é organizado em quatro partes: primeiramente, foi feita uma explanação de como se encontra o direito a liberdade religiosa na Constituição Federal de 1988. Em seguida, há uma análise acerca da tolerância religiosa como conduta fundamental para concretização deste direito, fundamentada em estudos encontrados tanto no campo do direito como no da ciência política. Num terceiro momento, busca-se trabalhar a secularização como modernização das instituições religiosas e sua permanência na sociedade. A quarta e última parte se reserva às considerações finais do trabalho. 


\section{Liberdade Religiosa na Constituição de 1988.}

Tem por destino o governo de um Estado democrático garantir aos seus cidadãos o reconhecimento e assegurar que todo homem tenha direito a crer de acordo com sua consciência, o que acaba por reafirmar os direitos de liberdade, que entre estes encontramos o direito à liberdade religiosa.

A Constituição brasileira de 1988, em consonância o artigo 18, da Declaração Universal dos Direitos Humanos, garante a liberdade de religião e de opinião, nos termos:

Todo homem tem direito à liberdade de pensamento, consciência e religião; este direito inclui a liberdade de mudar de religião ou crença e a liberdade de manifestar essa religião ou crença, pelo ensino, pela prática, pelo culto e pela observância, isolada ou coletivamente, em público ou em particular. (ONU, 1948)

E ratifica, no seu artigo $5^{\circ}$, nos incisos VI e VIII a liberdade de crença, o livre exercício dos cultos religiosos e a possibilidade de se invocar crença religiosa para se eximir de obrigação legal a todos imposta, desde que se cumpra prestação alternativa legalmente fixada. Porém, não se deve pensar que a noção de liberdade religiosa, em toda sua complexidade, se resuma à simples liberdade de crença ou a liberdade de culto. O princípio da liberdade religiosa ultrapassa a liberdade de crença e de culto para exigir, em pé de igualdade, a liberdade das organizações religiosas, que devem ser autônomas e soberanas em seus assuntos internos, como também exigirem que o Estado, por meio da cláusula da separação, venha a adotar condutas voltadas à preservação deste laicismo. O papel da laicização tem grande importância, pois a sua positivação surge da necessidade da completa separação dos campos religioso e político, com o significado de possibilitar o desenvolvimento tanto de um quanto de outro sem interferências, como bem comenta MACHADO, citando Hanna Arendt:

A secularização, longe de implicar uma hostilidade estadual relativamente ao fenômeno religioso, pode mesmo ser encarada como algo natural e desejável. Isso mesmo foi sublinhado por Hanna Arendt quando ela afirmou que a laicização, enquanto acontecimento histórico concreto, não é mais do 
que a separação da Igreja do Estado, da religião e da política, e isto, do ponto de vista religioso, evoca um regresso ao Cristianismo primitivo - dai a César o que é de César e a Deus o que é de Deus - mais do que uma perda de fé e de transcendência ou do que uma paixão reforçada pelas coisas do mundo. Assim compreendida, a idéia de secularização pode e deve ser compatibilizada com as exigências constitucionais em matéria religiosa. (MACHADO, 1996, p.97)

Portanto, verifica-se que a constituição brasileira está revestida de voluntarismo individual em matéria religiosa, protegendo um valor importante, o princípio da igualdade direcionado no sentido da fé, possuindo então um ordenamento de caráter jurídico protetor e pluralista. Ou seja, a constituição assegura a livre formação das opções religiosas dos indivíduos, e proporciona que as crenças (ou descrenças) disputem pela adesão de seus membros num cenário em que todas elas possuam igual dignidade entre si, não podendo o Estado, sob qualquer argumento, emitir juízos de valor quanto à validade, à verdade ou quanto à respeitabilidade de qualquer doutrina.

\section{Tolerância Religiosa}

Para que o direito à liberdade religiosa seja vivo no seio da sociedade, e não se torne letra morta, faz-se importante analisar a questão da tolerância religiosa, uma vez que o entendimento de liberdade religiosa está intimamente ligado a esta.

A idéia central de tolerância nasce quando os indivíduos em sociedade reconhecem o igual direito de convivência, e em dado momento a expressão de uma convicção torna-se uma necessidade:

(...) o núcleo da idéia de tolerância é o reconhecimento do igual direito a conviver, que é reconhecido a doutrinas opostas, bem como o reconhecimento, por parte de quem se considera depositário da verdade, do direito ao erro, pelo menos do direito ao erro de boa-fé. A exigência da tolerância nasce no momento em que se toma consciência da 
irredutibilidade das opiniões e da necessidade de encontrar um modus vivendi (uma regra puramente formal, uma regra do jogo), que permita que todas as opiniões se expressem. (BOBBIO, 2004, p. 215)

Ao falarmos de tolerância religiosa não devemos entendê-la como o ato de simples renúncia a uma convicção que se tem como certa no nosso íntimo, mas sim de saber que "a verdade tem tudo a ganhar quando suporta o erro alheio, já que a perseguição, como a experiência histórica o demonstrou com freqüência, em vez de esmagá-lo, reforça-o” (BOBBIO, 2004, p. 219).

Se convencer de que sua convicção não mais faz sentido, e encontrar outra convicção que se reveste de verdade absoluta para quem crer, deve surgir do íntimo do indivíduo e não de forma impositiva. É desta forma que a razão da tolerância religiosa encontra-se numa razão moral para com o próximo:

(...) pode-se aduzir em favor da tolerância uma razão moral: o respeito à pessoa alheia. Também nesse caso, a tolerância não se baseia na renuncia a própria verdade, ou na indiferença frente a qualquer forma de verdade. Creio firmemente em minha verdade, mas penso que devo obedecer a um principio moral absoluto: o respeito a pessoa alheia. Aparentemente, trata-se de um caso de conflito entre razão teórica e razão pratica, entre aquilo em que devo crer e aquilo que devo fazer. Na realidade, trata-se de um conflito entre dois princípios morais: a moral da coerência, que induz a pôr minha verdade acima de tudo, e a moral do respeito ou da benevolência em face do outro. (BOBBIO, 2004, p. 211)

É nesse sentido que um país tão plural como o Brasil, que tem como um dos reflexos dessa pluralidade diversas religiões de características tão peculiares, a tolerância possuir um papel tão importante como conduta, na medida em que essas diferenças só podem conviver quando se reconhece que a tolerância é o único caminho para uma sociedade que tem como um de seus principais fundamentos a liberdade. 


\section{A Secularização das Instituições Religiosas}

A secularização convive, ora de forma contraditória, ora de forma integrada, na lógica da modernidade. Tal lógica coloca o indivíduo, como medida de si, já não sendo mais o alicerce da união cultural-social posto pela religião, o que daria o sentido ordenador da realidade e do social, e sim sujeito da própria liberdade de escolha racional centrada no indivíduo autônomo.

Esse novo conceito ordenador da realidade e do indivíduo afeta tanto a sociedade como a religião, pois as instituições oficiais religiosas de representação perdem seu poder enquanto manipuladoras no mundo moderno, o que seria uma instituição enquanto definidora dos fundamentos da sociedade e das vidas, no coletivo. Neste sentido se reporta a Durkheim e Berger no entendimento de religião e da definição do fato social: "toda maneira de agir fixa ou não, suscetível de exercer sobre o indivíduo uma coerção exterior" (DURKHEIM, 1972, P. 46). Ainda segundo Durkheim, acerca de julgamentos de valor presentes na autoridade moral coletiva:

O julgamento social é objetivo em relação aos julgamentos individuais; a escala de valores encontra-se, assim, livre das apreciações subjetivas e variáveis dos indivíduos: estes encontram fora deles uma classificação estabelecida previamente, que não é obra sua, que não exprime seus sentimentos pessoais e com a qual são forçados a se conformar. Isto porque a opinião pública traz de suas origens uma autoridade moral pela qual se impõe aos particulares. (DURKHEIM, 1970, P. 54)

A religião/instituição já não tem a hegemonia definidora no campo da cultura, do Estado, do Direito, do lazer e entretenimento, enfim, das instâncias reguladoras do cotidiano. A laicização do Estado, como a separação das esferas civil e religiosa fizeram com que a religião se deslocasse de seu "centro irradiador de impacto de influência e poder de coesão totalizante sobre a vida social e cultural, e, portanto, sobre a vida e as escolhas do indivíduo" (PIERUCCI, 1997, P. 107). Tornando o individuo mais livre do que nunca, autônomo também na esfera simbólica. Tornando a identidade social, inclusive religiosa, algo privado.

Nesse contexto moderno secularizante, a religião - como instituição religiosa reguladora tradicional - já não tem o poder de regularizar o universo cultural, social e pessoal. 
Os indivíduos, contudo, continuam a viver dimensões religiosas, agora particulares, a partir da própria lógica da Modernidade: a autonomia racional (e também emocional) em compor o seu mundo. Assim, "a religião não termina com a secularização, mas ganha novas formas e contornos, novos sabores, numa dinâmica em que, ao mesmo tempo em que se esgota, se dilui, renasce, ressurge e se difunde" (HERVIEU-LÉGER, 1993, p. 36). Havendo então "uma recomposição da religião sob novas formas, mas com a perda de controle dos grandes sistemas religiosos que envolvia o todo social" (CAMURÇA, 2003, p. 63).

De acordo com Weber, pode-se falar de religiões substitutivas, sem referência a deuses, mas que conferem sentido ao cotidiano humano sem estruturar o social. "A estrutura do crer, da religião, diria, não é mais exclusivo das tradições religiosas tradicionais, mas é realizado pelos próprios indivíduos, estruturas e tradições várias que há" (HERVIEU-LÉGER, 1993, p. 58-59). A religião continua a existir também fora da "Igreja", disseminada de forma subjetiva e fragmentada. Assim sendo, a religião, na sociedade moderna, pode ser entendida de diferentes formas em relação ao modelo tradicional de outrora, ligado à conformação do sujeito a uma tradição religiosa/institucional ou reforçando a secularização enquanto indicativo de desregulamentação da religião/instituição antes monopolista.

Nessa lógica, a coesão comunitária também é enfraquecida, visto que o individualismo, em sua subjetividade religiosa, mina a instituição no senso de solidariedade coletiva, da obrigação religiosa com conseqüente e possível enfraquecimento de valores morais e da origem de identidade estável. Martin observa que "a erosão das estruturas eclesiásticas tradicionais reguladoras não se fez e faz tanto por questões ideológicas ou conceitos revolucionários explícitos, mas pelos comportamentos” (MARTIN, 1996, p. 29). Neste sentido, certezas e plausibilidades passam ao território privado, "como descobertas pessoais existenciais e, portanto, num viés psicologizado" (BERGER, 2004, p. 163).

Os chamados surtos emocionais dão o tom da religião na contemporaneidade conforme a experiência que questiona a religião regularizada, institucional e teologicamente racional/organizada. Por outro lado, pode-se apontar que esse mesmo fenômeno está na lógica da modernidade, de escolhas subjetivas, racionais e emocionais dos sujeitos. Entende-se uma dialética, pois "este emocionalismo antimoderno constituía, assim, e paradoxalmente, um modo de adaptação das religiões ao mundo moderno" (HERVIEU-LÉGER, 1997, p. 44).

A secularização, desse modo, revela o pluralismo religioso e vice-versa, onde se rompem monopólios religiosos de um único cosmos sagrado. Como chama Berger, religião é um "empreendimento humano pelo qual se estabelece um cosmos sagrado" (BERGER, 2004, p. 38), e se implanta o regime de concorrência entre os diversos agentes religiosos. Vale 
esclarecer que o processo de secularização não é um processo de enfraquecimento da religião, mas sim um processo de menor regulação institucional e menos influências tradicionais nos indivíduos, na sociedade e no Estado:

A secularização como processo de restrição continua à religião no mundo moderno. Para ele, os dados empíricos, longe de negar, reforçam o processo de secularização como causa e explicação da emergência dessa fermentação religiosa não-tradicional. $\mathrm{O}$ aumento do número e a variedade com que se configuram os novos movimentos religiosos implicam um declínio geral do compromisso religioso dos indivíduos para com qualquer sorte de definição ou credo, o que leva a ligações cada vez mais passageiras, reduzindo a religião a um item de consumo. Além disso, essas novas práticas religiosas tal qual as mais antigas - continuam a não ter nenhuma conseqüência nas estruturas e instituições sociais e de poder na Modernidade (CAMURÇA: 2003, p. 58-59).

Portanto, não se perde religião na sociedade atual, ela sofre mudanças, sendo o universo social laico, e o universo privado, religioso.

\section{Considerações Finais}

Sem o objetivo de esgotar as discussões empreendidas neste artigo sobre o referido tema, uma vez que sua relação com as diversas áreas das ciências humanas é notória, busca-se elucidar os interessados em direito e sociologia da religião no sentido de mostrar a amplitude do assunto, tanto no que diz respeito ao direito constitucional e sua história, como em sua imersão nas ciências sociais acerca das formas adquiridas pelas instituições da religião no tempo e espaço.

Conclui-se, pois, que as transformações ocorridas na sociedade, no âmbito da religião, tiveram suas modificações através do tempo acompanhadas pelo direito e pela sociologia, sendo possível esse diálogo segundo o qual o viés estudado pelos cientistas sociais bem como pelos juristas se completam, utilizando-se a própria história como alicerce, numa perspectiva complementar de como se entender a liberdade de religião hoje. 


\section{Referências:}

BERGER, Peter. O dossel sagrado. Elementos para uma teoria sociológica da religião. São Paulo: Paulus, 2004.

BOBBIO, Norberto. A era dos Direitos. Rio de Janeiro: Campus, 2004.

BRASIL. Constituição (1988) Constituição da República Federativa do Brasil. Brasília: Senado, 1988.168p.

CAMURÇA, Marcelo Ayres. Secularização e reencantamento: a emergência dos novos movimentos religiosos. In: BIB, São Paulo, número 56, 2003. p. 55-69

DURKHEIM, Émile. Julgamentos de valor e julgamentos de realidade. In: José Albertino Rodrigues (org.). Sociologia e Filosofia. São Paulo: Ática, 1993.

DURKHEIM, Émile. O que é fato social. In: José Albertino Rodrigues (org.). Sociologia e Filosofia. São Paulo: Ática, 1993.

HERVIEU-LÉGER, Danièle. La religion pour memoire. Paris : Cerf, 1993

HERVIEU-LÉGER, Danièle. Representam os surtos emocionais contemporâneos o fim da secularização ou o fim da religião?. In: Religião e Sociedade. 18/1, 1997. p. 31-48.

MACHADO, Jónatas Eduardo Mendes. Liberdade religiosa numa comunidade constitucional inclusiva: dos direitos da verdade aos direitos dos cidadãos. Coimbra: Coimbra Editora, 1996. (Boletim da Faculdade de Direito da Universidade de Coimbra STVDIA IVRIDICA, 18.)

MARTIN, David. Remise en question de la théorie de la sécularisation. In: GRACIE, Davis ; HERVIEU-LÉGER, Danièle (eds.) Identités religieuses en Europe. Paris : La Découverte, 1996.

ONU. Declaração Universal dos Direitos Humanos. 10 de dezembro de 1948.

PIERUCCI, Antônio Flávio. Reencantamento e dessecularização. A propósito do autoengano em sociologia da religião. In: Novos Estudos Cebrap, n. 49, nov., 1997. p. 99117.

Sobre os autores:

(1) Athena de Albuquerque Farias é Acadêmica do Curso de Ciências Sociais pela Universidade federal de Pernambuco - UFPE.

E-mail: athena.farias@gmail.com 
(2) João Matias de Oliveira Neto é Acadêmico do Curso de Ciências Sociais pela Universidade Federal de Campina Grande - UFCG.

E-mail: j.matias@msn.com

(3) Helayne Candido Pereira é Acadêmica do Curso de Direito pela Universidade Estadual da Paraíba UEPB.

E-mail: helayne_candido@hotmail.com

\section{Como citar este artigo (Formato ISO):}

FARIAS, Athena A.; OLIVEIRA NETO, J. M.; PEREIRA, H. C. Liberdade Religiosa: uma abordagem interdisciplinar. Id on Line Revista de Psicologia, sNovembro. 2009, vol.1, no.10, p.39-48. ISSN 1981-1189. 